\title{
A IDEIA AFROCÊNTRICA EM EDUCAÇÃO
}

\section{Molefi Kete Asante}

\section{Introdução}

Muitos dos princípios que orientam o desenvolvimento da ideia afrocêntrica em educação foram primeiramente estabelecidos por Carter G. Woodson na obra The Mis-education of the Negro (1933). De fato, este clássico de Woodson revela problemas fundamentais relacionados às pessoas africanas na América. Como Woodson sustenta, afro-americanos têm sido educados para ser alienados em relação às suas próprias culturas e tradições e presos às margens da cultura europeia; assim, deslocados de si mesmos, Woodson afirma que os afroamericanos frequentemente valorizam a cultura europeia em detrimento de sua própria herança (p. 7). Embora Woodson não defenda a rejeição da cidadania ou nacionalidade americana, ele acreditava que se os afro-americanos assumissem a mesma posição que os euro-americanos em relação às realidades dos Estados Unidos isto levaria à sua morte psicológica e cultural. Ademais, se educação deve ser sempre substantiva e significativa, no contexto da sociedade americana Woodson sustenta que primeiro ela deve tratar das experiências históricas africanas, no continente e na América (p. 7). Isto porque ele coloca na educação, e particularmente nas tradicionais faculdades afro-

\footnotetext{
* Artigo publicado em 1991 no Jornal of Negro Education. Tradução realizada por Ricardo Matheus Benedicto Professor do Instituto de Humanidades e Letras - Malês da Unilab, Coordenador do Curso de Pedagogia e Coordenador do Grupo de Pesquisa em Educação Afrocentrada. E-mail: ricardomb@unilab.edu.br.

** Professor e Coordenador do Departamento de Africologia e Estudos Afro-americanos da Universidade de Temple. E-mail: masante@temple.edu.
}

americanas o fardo de ensiná-los a serem responsáveis pela longa tradição e história da África tanto quanto a dos Estados Unidos. O alerta de Woodson reconhecendo, há mais de 50 anos, que algo está demasiadamente errado com o modo que os afroamericanos são educados forneceu o ímpeto principal para a abordagem afrocêntrica da educação americana.

Neste artigo examinarei a natureza e o escopo desta abordagem, estabelecerei sua necessidade e sugerirei caminhos para desenvolvê-la e disseminá-la por todos os níveis da educação. Duas proposições que estão no centro dos problemas teóricos e filosóficos serão apresentadas. Estas ideias representam o cerne dos pressupostos sob os quais tenho baseado a maioria dos meus trabalhos na área da educação, e eles sugerem a direção de meu pensamento sobre o que a educação é capaz de fazer por aqueles já marginalizados política e economicamente - afro-americanos:

1) Educação é fundamentalmente um fenômeno social cujo propósito e socializar o aprendiz; enviar uma criança para escola é prepará-la para tomar parte de um grupo social.

2) Escolas são reflexos da sociedade que as desenvolve (isto é, uma sociedade dominada pelo supremacismo branco desenvolverá um sistema educacional baseado na supremacia branca).

\section{Definições}

Uma estrutura alternativa sugere que outras definições e pressupostos podem oferecer um novo paradigma para o exame 
da educação na sociedade americana. Por exemplo, na educação, centricidade ${ }^{1}$ referese a perspectiva que envolve localizar os estudantes no contexto de suas próprias referências culturais para que eles possam relacionar-se social e psicologicamente com outras perspectivas culturais. Centricidade é um conceito que pode ser aplicado a qualquer cultura. O paradigma centrista é sustentado pela pesquisa mostrando que o método mais produtivo de ensinar qualquer aluno e colocar seu (sua) grupo no centro do contexto do conhecimento (ASANTE, 1990). Para os alunos brancos nos Estados Unidos isto é fácil porque a maioria das experiências discutidas são tratadas do ponto de vista da perspectiva e história branca. A educação americana, porém, não é cêntrica; é eurocêntrica. Consequentemente, estudantes não-brancos são levados a verem a si mesmos e seus grupos como "passivos" Raramente eles leem ou ouvem sobre pessoas não-brancas como participantes ativas na história. Isto é tão verdadeiro para a discussão da Revolução Americana quanto para a discussão sobre $O$ Inferno de Dante; por exemplo, muitos debates em sala de aula sobre o comércio de escravos europeu concentram-se nas atividades dos brancos mais do que na resistência e esforços dos africanos. Uma pessoa educada verdadeiramente de modo cêntrico verá a contribuição de todos os grupos como significativas e valorosas. Mesmo uma pessoa branca educada neste sistema não assumirá superioridade baseada em noções racistas. Assim, uma educação verdadeiramente cêntrica é dife-

${ }^{1}$ Os itálicos são do original.

${ }^{2}$ A expressão utilizada por Asante é “acted upon”. rente de uma educação eurocêntrica, racista (isto é, supremacista branca).

Afrocentricidade 3 é uma estrutura de referência na qual os fenômenos são vistos da perspectiva da pessoa africana. A abordagem afrocêntrica busca em toda situação a centralidade apropriada dos africanos (ASANTE, 1987). Na educação isto significa que os professores oferecem aos alunos a oportunidade de estudar o mundo e seus povos, conceitos e história do ponto de vista da visão de mundo africana. Em muitas salas de aula, qualquer que seja o objeto, os brancos estão localizados na perspectiva central. Quão estrangeira a criança afroamericana deve se sentir? Deve sentir-se como uma intrusa! A pequena criança afroamericana que sentada na sala de aula é ensinada a aceitar como heróis e heroínas indivíduos que difamam os povos africanos é ativamente des-centrada, deslocada e transformada em uma não pessoa, alguém cujo objetivo na vida pode ser um dia tirar aquele "crachá de inferioridade" da sua negritude. Na configuração educacional afrocêntrica, porém, professores não marginalizam as crianças afro-americanas criando nelas problemas de autoestima porque a história do seu povo raramente é contada. Para verem a si mesmos como sujeitos e não como objetos da educação - seja a área de estudo de biologia, medicina, literatura ou estudos sociais - os alunos afro-americanos verão a si mesmos não apenas como aqueles que buscam conhecimentos, mas como participantes integrais na construção dele. Como o conteúdo de todas as áreas são adaptáveis à abordagem afrocêntrica, os

\footnotetext{
3 Os itálicos são do original.
} 
estudantes afro-americanos ensinados a serem centrados na realidade de qualquer disciplina.

Deve-se enfatizar que a Afrocentricidade não ${ }^{4}$ é a versão negra do eurocentrismo. O eurocentrismo é baseado em noções de supremacia branca cujos propósitos são proteger o privilégio e vantagens da população branca na educação, na economia, na política e assim por diante. Diferentemente do eurocentrismo, a afrocentricidade condena a valorização etnocêntrica às custas da degradação das perspectivas dos outros grupos. Além disso, o eurocentrismo apresenta a história particular e a realidade dos europeus como conjunto de toda experiência humana (ASANTE, 1987). Ele impõe suas realidades como se fossem o "universal", isto é, apresentando o branco como representante da condição humana, enquanto todo não-branco é visto como um grupo específico, portanto, não "humano". Isto explica porque alguns acadêmicos e artistas afrodescendentes se apressam em negar sua negritude. Eles acreditam que existir como uma pessoa negra não é existir enquanto um ser humano universal. Eles são os indivíduos que Woodson identificou como aqueles que preferem a arte, a linguagem e a cultura europeia no lugar da arte, linguagem e cultura africana; eles acreditam que tudo que é de origem europeia é inerentemente melhor do que aquilo que é produzido ou realizado pelo seu próprio povo. Naturalmente, a pessoa de descendência africana deve estar centrada em sua experiência histórica, mas o currículo eurocêntrico pro-

\footnotetext{
4 Os itálicos são do original.
}

duz estas aberrações entre as pessoas de cor.

Multiculturalismo ${ }^{5}$ em educação é uma abordagem não hierárquica que respeita e celebra a variedade de perspectivas culturais sobre os fenômenos do mundo (ASANTE, 1991). A abordagem multicultural sustenta que embora a cultura europeia seja majoritária nos Estados Unidos, isto não é razão suficiente para que seja imposta sobre a diversidade da população estudantil como "universal". Multiculturalistas defendem que a educação, para ser justa, deve começar com a proposição de que todos os seres humanos contribuiram para o desenvolvimento do mundo e o fluxo de conhecimento e informação, e que a maioria das conquistas humanas são resultado de interação mútua e esforço internacional. Sem uma educação multicultural, os estudantes permanecem fundamentalmente ignorantes das contribuições da maior parte dos povos do mundo. Uma educação multicultural é, portanto, uma necessidade fundamental para qualquer um que deseja adquirir competência em qualquer assunto.

A ideia afrocêntrica deve ser um ponto de partida do qual a ideia multicultural deve começar. Uma autêntica educação multicultural, portanto, deve ser baseada sobre a iniciativa afrocêntrica. Se este passo é ignorado, o currículo multicultural, como tem sido definido progressivamente pelos brancos "resistentes" (eles serão discutidos abaixo), modificar-se-á sem qualquer infusão substantiva do conteúdo afroamericano, e a criança afro-americana con-

\footnotetext{
${ }^{5}$ Os itálicos são do original.
} 
tinuará perdida na estrutura eurocêntrica da educação. Em outras palavras, uma criança afro-americana não será reconhecida em (seu) sua própria informação cultural. Para benefício mútuo dos americanos, esta tragédia, que leva ao deslocamento psicológico e cultura das crianças afro-americanas pode e deve ser evitado.

\section{O Desafio Revolucionário}

Porque centra os estudantes afroamericanos dentro de sua história, cultura, ciência, ao invés de deixar de fora estes temas, a ideia afrocêntrica apresenta o maior desafio revolucionário para a ideologia da supremacia branca na educação nas últimas décadas. Nenhuma outra posição teórica sustentada pelos afro-americanos tinha capturado a imaginação de uma ampla variedade de acadêmicos e estudantes de história, sociologia, comunicação, antropologia e psicologia. O desafio afrocêntrico tem sido colocado em três caminhos críticos:

1) Questiona a imposição da visão supremacista branca como universal e/ou clássica (ASANTE, 1991).

2) Demonstra que as teorias racistas que atacam o multiculturalismo e o pluralismo são indefensáveis.

3) Projeta um ponto de vista humanista e pluralista ao articular a Afrocentricidade como uma perspectiva não hegemônica válida.

\section{Supressão e Distorção: Símbolos de Re- sistência}

As forças da resistência à transformação afrocêntrica e multicultural do currículo e às práticas de ensino começaram a organizar seus exércitos tão rapidamente quanto surgiram os textos sobre a necessidade de igualdade na educação (RAVITCH, 1990). Recentemente, o renomado historiador Arthur Schlesinger e outros formaram um grupo chamado Comitê para Defesa da História. Isto é uma consequência paradoxal, porque somente mentiras, inverdades e informações inacuradas precisam ser defendidas. Em seus argumentos contra a perspectiva afrocêntrica, estes proponentes do eurocentrismo frequentemente apresentam seus argumentos com categorias falsas e termos enganosos (i.e., "pluralista" e "multiculturalismo particularista”) (KETO, 1990; ASANTE, 1991). Além do mais, como o pensador Cheikh Anta Diop (1980) sustentava: "A história da Âfrica e a África não precisam de defesa”. A educação afrocêntrica não está contra a história. Ela está a favor ${ }^{6}$ da história - correta, acurada história - e se está contra alguma coisa, é contra a marginalização dos africano-americanos, hispano americanos, asiático americanos, nativo americanos e outras crianças não-brancas. O Comitê para Defesa da História não é nada mais do que uma tentativa fútil de reforçar os rachados pilares do sistema de supremacia branca que oculta seus verdadeiros motivos atrás da capa do liberalismo americano. Ele foi criado no mesmo espírito que gerou a obra de Allan Bloom The Closing of the American Mind (1987) e a de E. D. Hirsch Cultural Literacy: What Every American Need to Know (1987) que foram colocadas a serviço da hegemonia branca na educação, particularmente a hegemonia curricular. Este Comitê e as evidências do retrocesso branco são desafios previsíveis

\footnotetext{
${ }^{6}$ Os itálicos são do original.
} 
para o contemporâneo avanço de uma abordagem afrocêntrica e multicultural da educação.

Naturalmente, partidários diferentes de uma teoria terão visões distintas do seu significado. Enquanto dois discursos atualmente estão circulando sobre multiculturalismo, somente um é relevante para a liberação das mentes dos africanos e dos brancos nos Estados Unidos. Este discurso é o da afrocentricidade: a aceitação da África como central para os povos africanos. Todavia, ao invés de pegar carona com os afrocentristas na luta contra a hegemonia educacional branca, alguns brancos (e alguns negros também) têm optado por defender o retorno à educação escravizadora7. Infelizmente para eles, porém, estes dias se foram, e tal desinformação não pode mais - novamente - ser vendida como acurada, como educação correta.

Ravitch (1990), que sustenta que há dois tipos de multiculturalismo - multiculturalismo pluralista ${ }^{8}$ e multiculturalismo particularista -, é a líder daqueles professores que eu chamo de "resistentes" ou oponentes da afrocentricidade e do multiculturalismo. De fato, Ravitch promove uma divisão imaginária nas perspectivas multiculturais para esconder sua verdadeira identidade como defensora da supremacia branca. Sua tática é a daqueles que preferem que os africanos e outros não brancos permaneçam mental e psicologicamente escravos da civilização ocidental. Em sua arrogância, os resistentes acusam os afrocentristas e os

7 A expressão usada por Asante é "educational plantation".

${ }^{8}$ Os itálicos são do original. multiculturalistas de criar "fantasias históricas" e "teorias bizarras" sobre a contribuição dos povos não-brancos à civilização. $\mathrm{O}$ que eles provam, no entanto, é a sua própria ignorância. Além disso, Ravitch e outros (Nicholson, 1990) afirmam que o multiculturalismo causará a "tribalização" da América, mas na realidade a América sempre foi uma nação com diversidade étnica. Quando lemos seus trabalhos sobre multiculturalismo, percebemos que eles estão realmente defendendo a imposição da perspectiva branca sobre qualquer outra cultura. Acreditando que a posição eurocêntrica é inquestionável, eles tentam resistir e impedir a transformação progressiva do currículo monoétnico. De fato, o armário dos preconceitos se abriu revelando várias tentativas de pensadores brancos (em conjunto com alguns negros) de defender o privilégio branco no currículo da mesma forma que tem sido defendido com firmeza em outras áreas da sociedade. Talvez fosse inevitável que a introdução da ideia afrocêntrica levasse a discussão sobre o currículo das escolas americanas de um modo profundo.

Por que a afrocentricidade tem criado tanta controvérsia nos círculos educacionais? A ideia de que uma criança afroamericana localizada em uma posição forte para aprender se ele ou ela está centrada isto é, se a criança vê a si mesma ou a si mesmo no conteúdo do currículo e não nas suas margens - não é nova (ASANTE, 1980). O que é revolucionário é o movimento da ideia (estágio conceitual) para sua implementação na prática, quando começamos a ensinar os professores como colocar a juventude afro-americana no centro da instrução. Com efeito, os estudantes aprende- 
rão a ver com olhos novos e ouvir com novos ouvidos. A criança afro-americana aprenderá a interpretar e centrar o fenômeno no contexto da herança africana, enquanto os estudantes brancos serão ensinados a ver que o seu centro não está ameaçado pela presença ou contribuição dos afroamericanos e outros.

\section{A Condição da Educação Eurocêntrica}

Instituições, como as escolas, são condicionadas pelo caráter da nação na qual elas são desenvolvidas. Assim como o crime e a política são diferentes em diferentes nações o mesmo ocorre com a educação. Nos Estados Unidos a orientação "somente brancos" tem predominado no sistema educacional. Isto tem gerado um profundo impacto na qualidade da educação das crianças de todas as raças e grupos étnicos. A criança afro-americana tem sofrido de modo desproporcional, porém as crianças brancas também são vítimas da doença do currículo monocultural.

\section{A tragédia da ignorância}

Durante os últimos cinco anos muitos estudantes brancos e pais de alunos têm se aproximado de mim - após minha apresentação - com lágrimas nos olhos ou expressando sua raiva sobre a ausência de informação a respeito dos afro-americanos nas escolas. Um comentário recente de um jovem branco de uma grande universidade foi muito impressionante. Ele me disse: "meu professor nos disse que Martin Luther King era comunista e continuou com a aula.” Porque o professor deste estudante não se esforçou para discutir as ideias de King, o estudante, maliciosamente, foi mantido na ignorância. A imensa maioria dos americanos brancos são, do mesmo modo, ignorantes sobre o reservatório abundante e as contribuições da história africana e afroamericana. Por exemplo, poucos americanos de qualquer cor ouviram os nomes de Cheikh Anta Diop, Anna Julia Cooper, C.L.R. James ou J.A. Rogers. Todos eram historiadores que contribuíram enormemente para nosso entendimento do mundo africano. De fato, poucos professores fizeram curso no Departamento de Estudos Afro-americanos; portanto, a maioria é despreparada para oferecer informação sistemática sobre os afro-americanos.

\section{Afrocentricidade e História}

A maioria daqueles que ensinam na América são vítimas do mesmo sistema que vitimiza a juventude hoje. Assim, não se ensinam às crianças americanas os nomes dos grupos étnicos africanos do qual a maioria da população afro-americana descende; poucos são os que ensinam os nomes de qualquer lugar sagrado na África. Poucos professores discutem com seus alunos o significado da Passagem do Meio ou descrevem o que isto significou ou significa para os africanos. Pouca menção é feita nas salas de aula americanas sobre a brutalidade da escravidão ou sobre a celebração da liberdade dos ex-escravos. As crianças americanas têm pouca ou nenhuma compreensão sobre a natureza da captura, transporte e escravização dos africanos. Poucos aprendem os verdadeiros horrores de ser capturado, ser enviado nu por 25 dias ao longo do oceano, de ser destruído pelo abuso e indignidades de todos os tipos e desumanizado como um burro de carga, uma coisa sem 
nome. Se nossos estudantes soubessem somente a verdade, se a grande escravização lhes fossem ensinadas pela perspectiva afrocêntrica e se eles soubessem toda a história sobre os eventos desde a escravidão que tem servido constantemente para deslocar os afro-americanos, seu comportamento talvez fosse diferente. Entre estes eventos estão: o infame compromisso constitucional de 1787 que decretou que os afroamericanos eram, pela lei, equivalentes a três quintos de uma pessoa (ver FRANKLIN, 1974); a decisão do caso Dred Scott em 1857 na qual a Suprema Corte declarou os afroamericanos não tinham direitos que os brancos fossem obrigados a respeitar (HOWARD, 1857); a completa recusa e não execução da seção 2 da décima quarta emenda da constituição (esta emenda, aprovada em 1868, estipulou como uma de suas disposições uma penalidade contra qualquer estado que negasse aos afroamericanos o direito de votar e previa a redução dos delegados estaduais da Casa Representativa na proporção dos homens afroamericanos pobres); e a tão mencionada e ainda não recebida reparação pela escravidão de 40 acres e uma mula prometida a cada família afro-americana, depois da guerra civil, pelo general da União William T Sherman e o Secretário de Guerra Edwin Stanton (Oubre, 1978, p. 18-19, 182-183; ver também SMITH, 1987, p. 106-107). Se o currículo fosse melhorado para incluir a leitura das narrativas dos escravos; os diários dos capitães dos navios negreiros; os jornais dos senhores de escravos, os jornais dos abolicionistas; os escritos dos homens e mulheres livres; as explicações dos afro-americanos sobre os direitos civis, civismo e organiza- ções sociais; e numerosos outros fatos, as crianças afro-americanas seriam diferentes, as crianças brancas seriam diferentes - de fato, a América, hoje, seria uma nação diferente.

As salas de aula americanas deveriam repercutir o tratamento bárbaro dado aos africanos, como sua dignidade foi roubada e suas culturas destruídas. O registro das experiências dos escravos que escaparam, providencia a substância para estas unidades de aprendizagem. Por exemplo, a narrativa de Jacob e Ruth Weldon apresenta uma explicação detalhada da Passagem do Meio (Feldstein, 1971). Os Weldons observaram que os africanos que foram capturados e levados ao navio negreiro eram acorrentados ao convés, forçados a se abaixar e "marcados com ferro quente na forma de letras ou sinais mergulhados em uma preparação oleosa e pressionada contra seus corpos nus até queimar profundamente deixando cicatriz indelével para mostrar quem era o dono" (p. 33-37). Eles também relataram que aqueles que gritavam eram chicoteados no rosto, nos seios, nas coxas e nas costas com um "chicote de nove tiras"9 empunhado pelos navegadores brancos: "cada golpe trouxe as peças chicoteadas de carne enlutada” (p. 44). Eles viram "mães com bebes de colo marcados e chicoteados, cortados e cicatrizados de modo vil, como se o céu devesse ferir os algozes infernais com a desgraça que eles mereciam. Crianças e infantes não foram poupados deste terror. Os Weldon contaram que um bebê de nove meses, a bordo do navio negreiro, foi açoitado porque não queria comer. O capitão do

\footnotetext{
${ }^{9}$ A expressão usada por Asante é cat-o'-nine tails.
} 
navio ordenou que os seus pés fossem colocados em água fervente, para dissolver a pele e as unhas, e então ordenou que a criança fosse açoitada novamente, caso ainda se recusasse a comer. Eventualmente o capitão matava o bebe com suas próprias mãos e mandava a mãe da criança jogar o corpo ao mar. Quando a mãe se recusava, ela também apanhava e era forçada a ir à lateral do navio, onde "com a cabeça virada, para que não pudesse ver, ela jogava o corpo no mar" (p. 44). De modo similar, o capitão de um navio com 440 africanos a bordo observou que 132 teriam que ser atirados ao mar para economizar água (FELDESTEIN, 1971, p. 47). Outro escreveu: "o choro alto e sufocante (sic) por ar e comida vindo debaixo do convés adoeceu a alma da humanidade" (FELDESTEIN, 1971, p. 47).

Após chegar na América a situação era frequentemente pior. A brutalidade do sistema escravocrata é inigualável em relação a destruição psicológica e espiritual que se abateu sobre os afro-americanos. As mães escravizadas eram frequentemente forçadas a deixar seus filhos sozinhos enquanto trabalhavam nos campos. Impossibilitadas de cuidar deles de maneira adequada, elas frequentemente voltavam, à noite, do trabalho e os encontrava mortos (FELDESTEIN, 1971, p. 49). O testemunho de Henri Bibb também ilumina a desolação da experiência da escravidão:

Eu nasci em maio de 1815 , de uma mãe escrava... fui reivindicado como propriedade de David White... eu fui açoitado; de onde deveria receber instrução moral, mental e religiosa eu recebi inúmeras chicotadas, cujo objetivo era me degradar e me manter subordinada. Eu posso sinceramente dizer que eu bebi intensamente do copo amargo do sofrimento e da desgraça. Eu fui arrastado às profundezas da degradação e da miséria humana pelos senhores de escravos (FELDESTEIN, 1971, p. $60)$.

Escravidão era realmente a morte em vida. Enquanto o ataque ontológico motivou muitos africanos a optarem pelo suicídio, o resultado mais comum foi deslocamento, desorientação - todos eles consequências de a pessoa africana ser ativamente de-centrada. A época do "Jim Crow", período da cidadania de segunda classe - 1877 a $1954^{-}$, apresentou apenas uma ligeira melhora para a maioria dos afro-americanos. Esta era foi caracterizada pelo sistema de arrendamento, privação de direitos, segregação forçada, migração interna, linchamento, desemprego, péssimas condições de moradia e instalações educacionais separadas e desiguais. Políticas injustas e práticas que realmente atormentaram a raça.

Não é de se estranhar que muitas pessoas de descendência africana tentam abandonar sua raça e tornar-se "sem raça". A identidade básica de uma pessoa é a sua autoidentidade que, em última instância, é sua identidade cultural.; sem uma identidade cultural forte, a pessoa está perdida. Crianças negras não conhecem a história do seu povo e as crianças brancas não conhecem a história, mas a memória é um requisito vital para a compreensão e humildade. Por isso os judeus fizeram (corretamente, aliás) campanha para ter a história do Holocausto Europeu ensinada nas escolas e fa- 
culdades. Ensinar sobre esta monstruosidade e brutalidade humana deve lembrar, para sempre, o mundo as maneiras pelas quais os seres humanos frequentemente têm violado outros. Ensinar sobre o Holocausto Africano é tão importante pelas mesmas razões. Além disso, enfatiza a enormidade dos efeitos do deslocamento físico, psicológico e econômico da população africana na América e da diáspora. Sem o entendimento da experiência histórica dos povos africanos, as crianças americanas não farão qualquer progresso no enfrentamento dos problemas do presente.

Certamente, se as crianças africanas fossem ensinadas a ser plenamente conscientes das batalhas dos nossos ancestrais elas encontrariam um renovado senso do propósito e visão em suas próprias vidas. Elas parariam de agir como se não tivessem passado e nem futuro. Por exemplo, se lhes fossem ensinadas sobre a relação histórica dos africanos com a indústria do algodão como os homens, mulheres e crianças afroamericanas foram forçadas a colher algodão “do amanhecer até o anoitecer" até o sangue escorrer da ponta dos seus dedos onde eles foram picados pela cápsula dura; ou se elas pudessem visualizar seus ancestrais no sol tórrido, constantemente curvados, e arrastando ásperos e pesados sacos de corvina atrás de si - ou se elas os imaginassem trazendo estes sacos tremendo e temerosos de serem açoitados, caso eles não pegassem o suficiente, talvez nossa juventude afroamericana desenvolvesse um forte espírito empreendedor. Se fosse ensinado às crianças brancas estes mesmos conhecimentos, ao invés do que lhes é normalmente ensinado sobre a escravidão americana, elas provavelmente veriam nossa sociedade de um modo diferente e trabalhariam para transformá-la em um lugar melhor.

\section{Corrigindo Informações Distorcidas}

Educação hegemônica só pode existir enquanto a informação acurada e verdadeira for sonegada. Educação hegemônica eurocêntrica somente pode existir enquanto os brancos sustentarem que africanos e outros não-brancos nunca contribuíram para a civilização mundial. É, em grande medida, sobre tais ideias falsas que distinções errôneas são feitas. A verdade, no entanto, nos dá o discernimento dos reais motivos por trás das ações humanas, se alguém escolhe seguir o caminho dos outros ou não. Por exemplo, nenhuma pessoa pode ficar confortável ensinando que a arte e a filosofia nasceram na Grécia se ela aprender que os próprios gregos ensinaram que o estudo destas disciplinas começou na África, especialmente no antigo Kemet (HERÓDOTO, 1987). Os primeiros filósofos foram os egípcios Kagemni, Khun-anup, Ptha-Hotep, Khéti e Seti; mas a educação eurocêntrica é tão desarticulada que os estudantes não têm meios de descobrir estes e outros conhecimentos da relação orgânica da África com o resto da humanidade. Não somente a África contribuiu para a história humana, as civilizações africanas precedem todas as outras. De fato, as espécies humanas originaram-se no continente africano - esta é a verdade se observarmos as evidências arqueológicas ou biológicas.

Outras duas noções devem ser refutadas. Existem aqueles que que dizem que a história afro-americana deve começar com a chegada dos africanos como escravos em 
1619, mas foi demonstrado que os africanos visitaram e habitaram a América do Norte e do Sul muito antes dos colonizadores europeus "descobrirem" o Novo Mundo" (VAN SERTIMA, 1976). Em segundo lugar, embora a América tenha se tornado algo como uma casa para os africanos que sobreviveram aos horrores da Passagem do Meio, suas experiências nos navios negreiros durante a escravidão resultaram numa perspectiva sobre a América completamente diferente (e frequentemente contaminada) dos europeus e outros que vieram, na maioria dos casos, de livre e espontânea vontade buscando oportunidades que não estavam disponíveis em sua terra natal. Afrocentricidade, portanto, procura reconhecer esta divergência quanto a perspectiva bem como criar centralidade para os alunos afro-americanos.

\section{Conclusão}

A iniciativa dominante para uma reforma curricular total é o movimento que está sendo proposto e liderado pelos africanos, a saber, a ideia afrocêntrica. Quando eu escrevi o primeiro livro sobre a afrocentricidade (ASANTE, 1980), agora em sua quinta edição, eu não imaginava que em 10 anos a ideia sacudiria e embasaria as discussões sobre educação, arte, moda e política. Desde a publicação de meus trabalhos subsequentes, The Afrocentric Idea (ASANTE, 1987) e Kemet, Afrocentricity na Knowledge (ASANTE, 1990), o debate tornou-se mais sério. Apesar disso, para muito brancos americanos (e alguns afro-americanos) o mais inquietante aspecto da discussão sobre a afrocentricidade é que sua fonte intelectual se encontra nas pesquisas e trabalhos de intelectuais afro-americanos. Os brancos estão acostumados a serem responsáveis pela maioria das ideias em circulação na academia americana. Desconstrucionismo, psicologia Gestalt, marxismo, estruturalismo, teoria piagetiana, e assim por diante, têm sido desenvolvidas, articuladas e elaboradas geralmente por intelectuais brancos. De outro lado, a afrocentricidade é produto de pensadores tais como Nobles (1986), Hilliard (1978), Karenga (1986), Keto (1980), Richards (1991) e Myers (1989). Há também um aumento de jovens intelectuais afroamericanos impressionantemente credenciados que começaram a escrever de modo afrocêntrico (JEAN, 1991). Eles, e alguns jovens pensadores brancos, têm sugerido ideias sobre como mudar o currículo afrocentricamente.

A afrocentricidade oferece a todos os americanos a oportunidade de examinar a perspectiva da pessoa africana nesta sociedade e no mundo. Os resistentes afirmam que a afrocentricidade é antibranca; já, se a afrocentricidade, como teoria, é contra alguma coisa é contra o racismo, ignorância e a hegemonia monoétnica no currículo. A afrocentricidade não é antibranca; ela é, entretanto, pró-humano. Além do mais, o objetivo do currículo afrocêntrico não é dividir a América, e sim fazê-la prosperar como deveria. Esta nação, há muito tempo, tem sido dividida com relação as oportunidades educacionais oferecidas às crianças. Em virtude da proteção oferecida pela sociedade e reforçada pelo currículo eurocêntrico, as crianças brancas já estão a frente das afro-americanas desde a primeira série. Nossos esforços, então, devem se concentrar em dar, às crianças afro-americanas, grandes oportunidades de aprendizagem 
desde o jardim de infância. No entanto, o tipo de assistência que a criança afroamericana necessita é tanto cultural quanto acadêmico. Se é oferecida informação cultural adequada, o rendimento acadêmico certamente será satisfatório.

Quando se trata de educar crianças afroamericanas, o sistema educacional americano não necessita de ajustes, ele precisa de uma revisão geral. Crianças negras têm sido difamadas por este sistema. A história negra tem sido difamada. A África tem sido difamada. Não obstante, dois truísmos podem ser sustentados sobre a educação na América. Primeiro, alguns professores podem ${ }^{10} \mathrm{e}$ efetivamente ensinam as crianças afroamericanas; segundo, se alguns professores podem fazê-lo, outros também podem. Nós devemos aprender tudo o que pudermos sobre o que torna estas atitudes e abordagens dos professores um sucesso, e então, trabalhar diligentemente para ver que seus sucessos são replicados em uma escala maior. Levantando as mesmas questões que Woodson colocou há mais de 50 anos, a educação afrocêntrica, em conjunto com uma reorientação significativa do sistema educacional americano, parece responder ao deslocamento psicológico e cultura da pessoa africana. Oferecendo uma diretriz filosófica e teórica e critérios que são centrados na percepção africana da realidade e colocando a criança afro-americana em sua ou seu contexto histórico e ambiente adequado, a afrocentricidade pode ser justamente a "válvula de escape" que os afroamericanos tão desesperadamente necessitam para facilitar o sucesso acadêmico e

\footnotetext{
${ }^{10}$ Os itálicos são do original.
}

"romper" o ciclo de deseducação e deslocamento. 


\section{Referências}

ASANTE, Molefi. K. Afrocentricity: The theory of social change. Buffalo, NY: Amulefi, 1980. The Afrocentric Idea. Philadelphia: Temple University Press, 1987.

\footnotetext{
_. Kemet, Afrocentricity and Knowledge. Trenton, New Jersey: Africa World Press, 1990.
}

BLOOM, Allan. The closing of the American mind. New York: Simon \& Schuster, 1987. FELDSTEIN, S. Once a slave: The slave's view of slavery. New York: William Morrow, 1971.

FRANKLIN, J. H. From slavery to freedom. New York: Knopf, 1974.

HERODOTUS. The History. Chicago: University of Illinois Press, 1987.

HILLIARD, Asa. G., III. (1978, June 20). Anatomy and dynamics of oppression. Speech delivered at the National Conference on Human Relations in Education, Minneapolis, MN.

HIRSCH, E. D. (1987). Cultural literacy: What every American needs to know. New York: Houghton Mifflin, 1987.

HOWARD, B. C. (1857). Report of the decision of the Supreme Court of the United States and the opinions of the justices thereof in the case of Dred Scott versus John F. A. Sandford, December term, 1856. New York: D. Appleton \& Co.

JEAN, C. Beyond the Eurocentric veils. Amherst, MA: University of Massachusetts Press, 1991.

KARENGA, Maulana. R. Introduction to Black Studies. Los Angeles: University of Sankore Press, 1986.

KETO, C. T. (1990). Africa-centered perspective of history. Blackwood, NJ: C. A. Associates, 1990

NICHOLSON, D. (1990, September 23). Afrocentrism and the tribalization of America. The Washington Post, p. B-i.

NOBLES, Wade. African psychology. Oakland, CA: Black Family Institute, 1986

OUBRE, C. F. Forty acres and a mule: The Freedman's Bureau and Black land ownership. Baton Rouge, LA: Louisiana State University Press, 1978.

RAVITCH, Diane. (1990, Summer). Multiculturalism: E pluribus plures. The American Scholar, 1990, p. 337-354.

RICHARDS, D. Let the circle be unbroken. Trenton, NJ: Africa World Press, 1991.

SMITHS, J. O. The politics of racial inequality: A systematic comparative macro-analysis from the colonial period to 1970. New York: Greenwood, Press, 1987.

VAN SERTIMA, Ivan. They came before Columbus. New York: Random House, 1976.

WOODSON, Carter. G. The education of the negro prior to 1861: A history of the education of the colored people of the U.S. from the beginning of slavery. New York: G. P. Putnam's Sons, 1915.

. The mis-education of the negro. Washington, DC: Associated Publishers, 1933. 
African background outlined. Washington, DC: Association for the Study of AfroAmerican Life and History, 1936.

Recebido em: 05/06/2019

Aprovado em: 31/10/2019 